\title{
Integrated marketing communications and their role in economy and education
}

\author{
Nadezhda Melnikova ${ }^{1}$, Tamara Naumenko ${ }^{1}$ and Natalia Smakotina ${ }^{1, *}$ \\ ${ }^{1}$ Lomonosov Moscow State University, Globalistics department, Faculty of global studies, Moscow, Russia
}

\begin{abstract}
The article is devoted to the analysis of marketing, its role and significance in the modern education system and economy. The authors review the advantages of integrated marketing communications which include, apart from marketing, organizational culture, advertising, public relations (PR), branding, image making and other types of communication influencing the formation and functions of social processes and institutions, including the economic and education sphere.
\end{abstract}

World history continues to evolve steadily, meaning that the pace of globalization of all processes taking place in the social and economic sphere increases. We are now able to talk about the global economic area which functions on the global level and is characterized by the active integration processes on the one hand, and the tendencies for regionalization and local socio-economic mechanisms on the other hand.

Taking into consideration the current socio-economic dynamics, marketing communications, aimed at marketing and selling of goods as well as developing the economic policy of regions and states and optimizing the world economy, start to play an important role in the coordination and development of all economic processes.

In the course of marketing communication, which represents systematic relations between the enterprise and the market, marketing experts accumulate the ideas, solutions, communication details that are then used to stimulate the positive consumer perception of the goods and services. The result of this generalization is a communication set, which is formed with the help of marketing communication instruments devised to be compatible, to meet the target market and enhance sales and consumer awareness.

To achieve a desirable external communication effect an organization must have a certain organizational culture, appropriate management and structure. Otherwise, if the communication programs do not correspond to the corporate spirit, the company will be unable to maintain a stable image for the consumers, shareholders and its staff.

As an example we shall analyze the organizational (corporate) culture of the research companies OOO "Romir" ("Romir, LLC") and OOO "Profi reseach" ("Profi reseach, LLC") and measure their efficiency. The main sphere of these companies is marketing research.
The dynamics of the research company "Romir" data obtained during an unstructured interview showed the differences in the respondents' perception of the organizational culture. The main guide for non-formal interview was aimed at revealing the features of the organizational culture of Russian research companies, their nature and type. The selection of respondents depended on the total amount of the company employees: "Romir" - 5 respondents, «Profi research» 10 respondents. The interview was conducted by Y.V.Plaksina, the master student of the High School of Modern Social Sciences (Lomonosov Moscow State University) as a part of her sociological research in May 2015 (the title of the master thesis is "The specific character of the organizational culture in Russian research companies", scientific supervisor: Doctor of Science (Dr. hab.), professor N.L.Smakotina). The company "Profi research" showed the lack of significant differences in the respondents' perception of the organizational culture, which shows the lack of a unified concept of organizational culture, its strong dynamic vibrations.

The overall trends were identified in the type of organizational culture when the dynamic performance of the internal level of both companies was compared (the respondents described the "Order" variety of organizational culture). The companies were shown to bear resemblance to the "Team" type of culture which can be explained by the type of their scientific research.

The "Club" variety of organizational culture was identified as the dominating one in "Romir". This type of culture can be characterized as "loyal". There is dedication and harmony between employees and strong teamwork. This type of organizational culture is also marked by stable and safe working conditions, strong promotion of the employees of the older age group, due to their experience and official advantage. Career growth is gradual in the company with this kind of culture.

Corresponding author: smakotina@mail.ru 
It is expected from the employee that he or she will grasp all the peculiarities of work and master the skills at each new level which is why the employees of such companies often have broader professional horizons.

The "academic" type of organizational culture turned out to be dominant in the company "Profi research" which is supposed to be a negative indicator for a research company today.

The dichotomy between "academic" and "club" type of culture is the most difficult point in the company analysis, as the former is historically typical for Russia, and the latter is more common in Europe.

It may be concluded that "Romir" as a more experienced company consciously maintains this type of culture for the purpose of sustaining internal dynamics, motivation of employees and development of their personal and professional competencies, as well as for maintaining the rapid pace of growth and development of the whole company. This is in its turn supported by the research companies" ratings where "Romir" holds the leading position.

"Profi research" is characterised by a more traditional view of culture, which causes an imbalance of the main indicators, hampers employee orientation in the internal affairs of the company, limits his or her professional and personal development in many ways.

Modern marketing is characterized by a significant change in the communication landscape as a result of the emergence of new mixed information technologies and systems that lead to an increase of the incoming information intensity and the amount of marketing communication tools. As a result, various communication sets may compete with each other to attract the attention of the same customers and, therefore, it may be difficult to select the most efficient set of communication tools in terms of the impact on consumers.

The marketing strategy is to a great extent based on the communicative aspect, that is why the modern marketing sphere is increasingly called 'integrated marketing communications', and includes not only direct marketing, but also such types of communicative practices as advertising, public relations, branding, image making and dealing with the media.

Advertising is a special form of communication technology, and its marketing function is not limited to informing the public. That is why advertising is one of the main means of promoting products or services and one of the main elements of integrated marketing communications [1]. It mainly consists of impersonal forms of communication established through paid media channels. The effective advertising campaign presupposes setting goals, budget setting (which fully depends on the financial capacity of the enterprise), development of the effective advertising messages, selection of the appropriate media support, evaluating the proposals for the adjustments in future advertising. Moreover, when the advertising campaign of any institution or company is being developed one should define the target audience, the necessary coverage and frequency of advertising messages, to describe the desired response, because the effectiveness of the advertising messages is to a large extent determined by the consumer reaction and feedback. Advertising should convince people to follow the marketing strategy, whose main aim is to sell the desirable product profitably. The advertisement should influence the consumer's choice and his or her purchase decision. This task of advertising becomes apparent from the definition of advertising, claiming that advertising is a means of informing the customer for the purpose of sale ('advertising is the means of making known in order to sell' [2]). Frank Jefkins and Daniel Yadin in their book Advertising give the example of three companies ('Stork', 'White Horse' or 'Silk Cut') and_emphasize the idea that advertising makes the communication process more sophisticated and informs us about the product in a certain way to make us buy it, although sometimes the name of the product (brand) itself does not give the direct clue as to what kind of product is being advertised. The list of such companies can be expanded with the names of several Russian brands: 'Makfa', 'Yandex', 'Savage'.

In the context of market relations the effectiveness of marketing communications aimed at marketing optimization and achieved by full consumer satisfaction becomes one of the main factors of economic stability of business entities. Today, however, the companies begin to enhance the development of integrated marketing communications that form the basis for all areas of market activity and are devised to meet the needs of the whole society. They serve as an important tool of public relations in a market economy [3].

The effective use of integrated marketing communications and the implementation of new management methods require, first and foremost, defining and understanding of the concept "integrated marketing communications" (IMC). There have been various interpretations of the term "integrated marketing communications". It is considered that the concept of "integrated marketing communications" combines all the tools of marketing communications, from advertising to packaging, from a system of messages to a certain slogan [4]. IMC use all means of marketing communications, which transfer marketing messages to the target audience.

Successful company management today requires long-term focusing on specific consumer products and services, not on the whole segments of the market. That is why the stable competitive position of the company in the market is provided by integrated marketing communications that form a single functional direction in which all the marketing tools are coordinated and based on the use of a single logo [5]. This is a relatively new approach which helps to understand the notion from the customers' point of view.

When using the IMC one should also take into account their specific feature - providing more attention to consumers who purchase goods or services, not just delivering the sales growth.

The essence of the IMC lies in the coordinated communications, based on the needs of consumers and the unique features and value of products which distinguish them from the competing brands in the consumer's mind. If the value is perceived as the best 
one, the consumer will prefer your company. However, it is a difficult task for the company to convince consumers of the need to purchase or use this particular product or service. The incentive arguments are needed to understand why one should use the services of the company, rather than give preference to the competitors' services [6]. The skillful use of integrated marketing communications enables the company to win the trust of its target audience and to convince customers of exceptional quality and unique features of the product.

To use IMC effectively one needs to identify the target audience and develop a well-coordinated programme (concept) of promotion to achieve the desired consumer response [7].

When creating the IMC it is vital to establish a common programme or plan for the campaign, to consider personal sales, sales promotion and public relations features [8]. However, this approach only partially reveals the complex elements of the IMC, as the means and methods used by these communications are much broader and go beyond the use of the methods mentioned above. Today companies can use the IMC, which combine advertising, direct marketing, the promotion system, personal sale, public relations, marketing publications, exhibition marketing, interactive marketing, corporate identity, sponsorship, unplanned communication, etc.

There is a need for coherence and coordination of all efforts in a company to promote the products and services. The use of integrated marketing communications becomes essential and allows a company to integrate individual messages into one message to ensure consistent targeting of various groups of recipients. Marketing communications are one of the main instruments of the marketing strategy and the practical implementation of the market aims of the organization.

Some researches suppose that the companies need to create their own channels of communication and devise their communication strategy [9]. The set of these communication strategies is based on the analysis of main components, criteria and stages of communication strategy development, as the character and features of the organization are often reflected in its external communication [10]. The process of external communication with the target audiences, its structure and functioning on different levels is defined as integrated marketing communications (IMC).

The main goal of the IMC is to select the optimal combination of the elements of integrated marketing communications, which will most effectively transfer the necessary information to the target audience. If the choice is correct, the various communication elements will reinforce each other and will have the major impact on the consumer. The right order of the IMC elements plays an important role, since the use of one of them often gives rise to other opportunities.

For example, advertising of university's educational services may encourage applicants to contact it directly by e-mail or by phone or even to visit it to receive detailed information. The Internet is rapidly developing and becoming an increasingly important form of communication between universities and future applicants, their parents, relatives and other interested parties. This leads to significant changes in marketing strategies of universities. People around the world spend more time on the web, using computers, tablets and smartphones and paying less attention to other means of communication. Modern universities realize the importance of this communication medium and create official Web-sites and social network pages that contain information about the educational services, profession, area of expertise (on the bachelor, master, specialist, post-graduate, doctoral level), tuition fees, employment opportunities for students. They also add the information about the dormitories, sports stadiums, swimming pools, university cultural centers, festivals and other events organized by the educational institution. In addition, the website usually highlights various events of the university life, such as meetings with famous people, prominent representatives of different spheres of modern life, including foreign lecturers and visiting professors. Moreover, it is crucially important to attract Russian and foreign school graduates both to state-funded and feebased programs by offering them relevant and detailed information about the ways the university links the world of science and technology to education and society in general, about the university-industry partnerships and internship programs it offers, etc.

Effective public relations (PR) form an indispensable part of integrated marketing communications for most businesses and educational institutions. For example, universities are constantly interacting and cooperating with the public and forming public opinion about the institution and the quality of education it provides [11].

Rationally organized PR allows the university to establish effective cooperation with the community and to build and reinforce the positive public opinion about the quality of its educational services including general and specialized training [12]. A well-developed PR programme enhances the credibility of the university and creates its positive image. The positive image of any company or organization improves its competitiveness in the market, attracting customers and partners, increasing the volume of sales of goods or services and, as a consequence, the profit of the company or institution.

University graduates play a special role in shaping its image [13]. The long-term relationships with alumni can include observation of their career paths, creating an Alumni Club as part of a horizontal network of mutual assistance, encouraging graduates to take part in the university life. The long-standing relationship with the graduates serves two important functions:

- creation of an informal community of people who are connected to the university. The participants' benefits depend on how strong the brand of their institution is;

- the university as a community center - only graduates who keep in touch with the university will give it financial, information and lobbying support.

It is of utmost importance, that usually the graduates represent various fields of activity, they do not act directly on behalf of the institution, and they can provide other graduates with considerable business or economic 
opportunities. Thus, graduates tend to achieve much more, because the synergistic relationship is being fostered in the alumni association.

Companies may also effectively use exhibition as a form of communication with the public because it provides simultaneous distribution of a wide range of economic, technical and commercial information about the company or educational institution. This type of communication with the public is used in order to increase the competitiveness of the company and also to receive economic, technical and commercial information [14]. Exhibitions help to facilitate the exchange of information, to provide the opportunity to compare similar goods and services, their terms of sale, quality and price. It also allows university representatives to communicate directly with the target audience, to establish professional contacts, etc.

Thus, it is possible to conclude even from this brief analysis that the marketing itself, as well as integrated marketing communications, perform a fundamental role not only in the sales of goods and services, but also in the harmonization and coordination of the economic, social, organizational and administrative spheres of society.

\section{References}

1. O.Yu. Kornienko, Economy and management: issues and solutions, 6, 138-142 (2015).

2. F. Jefkins, and D. Yadin, Advertising (Prentice Hall, 2000).

3. J. Lambin and I. Schuiling, Market-Driven Management: Strategic and Operational Marketing, (Palgrave Macmillan, 2012).

4. F.I. Sharkov, Modern marketing communications. A reference book (Moscow, Alpha-press, 2006).

5. D.E.Schultz, S. Tannenbaum, and R.F. Lauterborn, The New Marketing Paradigm: Integrated Marketing Communications, (McGraw-Hill, 1996).

6. I.M. Sinyaeva, Intergrated marketing communications (Moscow, Unity-Dana, 2012).

7. E.G. Becker, T.N. Burdelova, and A.Y. Yudanov, Brand and the economic stability of university, (Moscow, KnoRus publishing, 2012).

8. M.R. Solomon, Consumer Behavior: Buying, Having, and Being (Pearson, 2014).

9. G.A. Churchill, and T.J. Brown, Basic Marketing Research (South-Western College Pub, 2006).

10. W. Jan, Promocja. System komunikacji przedsiębiorstwa z rynkiem (Kharkov, Humanitarian Centre publishing, 2003).

11. I.N. Krasyk, Marketing communications (Moscow, Infra-M, 2013).

12. O.S. Suvorova, Economy and management: issues and solutions, 6, 83-88 (2015).

13. T.A. Gaydaenko, Marketing management, (Moscow, Eksmo, 2006).

14. D. Cravens, and N. Piercy, Strategic Marketing (McGraw-Hill Education, 2012). 